\title{
CAPITAL INTELECTUAL E O SISTEMA DE CONTROLES GERENCIAIS DAS INSTITUIÇÕES PÚBLICAS DE ENSINO SUPERIOR: UM ENSAIO TEÓRICO SOB A PERSPECTIVA DA TEORIA DA CONTINGÊNCIA
}

\section{RESUMO}

O contexto econômico evoluiu para a era do conhecimento. Nesse sentido, os recursos relacionados ao capital intelectual ganham destaque como um determinante para lidar com as variáveis contingenciais. O fator que impulsiona o capital intelectual é o capital humano, recurso intensivo em instituições públicas de ensino superior, fato que justifica o presente estudo, com o objetivo de discutir a influência do capital intelectual nos sistemas de controle de gestão de universidades públicas, sob a perspectiva do capital intelectual como fator contingencial. Realizou-se pesquisa bibliográfica, a fim de atingir o objetivo proposto. Percebe-se falta de desenvolvimento da literatura relacionada ao tema, um cuidado ainda incipiente, com o capital humano nas instituições públicas de ensino superior.

Palavras-chave: Capital Intelectual; Controle Gerencial; Instituições de Ensino Superior Públicas; Setor Público.

\section{INTELLECTUAL CAPITAL AND THE SYSTEM OF MANAGEMENT CONTROLS IN PUBLIC INSTITUTIONS OF HIGHER EDUCATION: A THEORETICAL ESSAY FROM THE PERSPECTIVE OF CONTINGENCY THEORY}

\begin{abstract}
The economic context has evolved into the era of knowledge. In this sense, the resources related to intellectual capital gain prominence as a key to deal with the contingency variables. The factor that drives intellectual capital is the human capital, an intensive resource in public institutions of higher education, which justifies the present study, in order to discuss the influence of intellectual capital in public universities management control systems, under the perspective of intellectual capital as a contingency factor. We conducted a literature search in order to achieve the proposed objective. It is perceived lack of development of literature related to the theme, a fledgling care, with human capital in public institutions of higher education.
\end{abstract}

Keywords: Intellectual Capital; Management Control; Public Higher Education Institutions; Public Sector. 
Capital Intelectual e o Sistema de Controles Gerenciais das Instituições Públicas de Ensino Superior: Um Ensaio Teórico sob a Perspectiva da Teoria da Contingência

\section{CAPITAL INTELECTUAL Y GESTIÓN DEL SISTEMA CONTROLES DE LAS INSTITUCIONES PÚBLICAS DE EDUCACIÓN SUPERIOR: UNA PRUEBA TEÓRICA BAJO EL PERSPECTIVA DE LA TEORÍA DE LA CONTINGENCIA}

\section{RESUMEN}

El contexto económico ha evolucionado hasta convertirse en la era del conocimiento. En este sentido, los recursos relacionados con la prominencia ganancia de capital intelectual como elemento clave para hacer frente a las variables de contingencia. El factor que impulsa el capital intelectual es el capital humano, exige muchos recursos en las instituciones públicas de educación superior, lo que justifica el presente estudio, con el fin de analizar la influencia del capital intelectual en sistemas de control de gestión de las universidades públicas en el marco del perspectiva del capital intelectual como un factor de contingencia. Se realizó una búsqueda en la literatura con el fin de alcanzar el objetivo propuesto. Se percibe la falta de desarrollo de la literatura relacionada con el tema, una atención incipiente, con capital humano en las instituciones públicas de educación superior.

Palabras clave: Capital Intelectual; Control de Gestión; Instituciones Públicas de Educación Superior; Sector Público.

Thiago Cesar Bezerra Moreno ${ }^{1}$ José Luiz Borsatto Junior ${ }^{2}$ Delci Grapégia Dal Vesco ${ }^{3}$ Silvana Anita Walter ${ }^{4}$

\footnotetext{
1 Mestrando em Contabilidade pela Universidade Estadual do Oeste do Paraná - UNIOESTE. Brasil. E-mail: tmoreno2@gmail.com

${ }^{2}$ Mestrando em Contabilidade pela Universidade Estadual do Oeste do Paraná - UNIOESTE. Professor do Curso de Ciências Contábeis da Universidade Paranaense - UNIPAR. Brasil. E-mail: junior.borsatto@yahoo.com.br

${ }^{3}$ Doutora em Ciências Contábeis e Administração pela Univiversidade Regional de Blumenau - FURB. Professora da Universidade Estadual do Oeste do Paraná - UNIOESTE. Brasil. E-mail: delcigrape@gmail.com

${ }^{4}$ Doutora em Administração pela Pontifícia Universidade Católica do Paraná - PUC/PR. Professora da Universidade Estadual do Oeste do Paraná - UNIOESTE. Brasil. E-mail: silvanaanita.walter@gmail.com
} 


\section{INTRODUÇÃO}

A nova economia, anunciada por Drucker (1993), é referida como a sociedade do conhecimento. Nesta sociedade, o conhecimento é o único recurso relevante, pois consiste num recurso compartilhável entre os integrantes da organização e está ligado à história e experiências da empresa. Para melhor entendimento e gerenciamento, o conhecimento pode ser dividido em três dimensões: capital humano, capital estrutural e capital relacional (Bontis, 1998).

Bontis (1998) explica que o capital intelectual envolve três perspectivas: o capital humano, em que sua essência é gerida pela inteligência dos membros da empresa; o capital estrutural que refere-se à forma que o capital humano é organizado internamente nas organizações, de modo a incorporá-lo nas rotinas empresariais - tornando-o assim, proveitoso para os objetivos das organizações -; e por fim, o capital relacional é o recurso externo às organizações, diz respeito ao relacionamento com clientes e canais de marketing, por exemplo.

Instituições de ensino superior (IES) concentram uma quantidade elevada de capital humano oriundo de seu quadro de colaboradores (Ph.D., Dr., mestres e especialistas), motor gerador de capital intelectual (CI), que, por sua vez, relaciona-se com o desempenho dessas entidades. Portanto, os recursos mais valiosos de uma universidade são os seus pesquisadores e estudantes com suas relações e rotinas organizacionais, sua produção mais importante é o conhecimento. Esses recursos podem ser interpretados como ativos intangíveis ou capital intelectual (Leitner, 2004). Deste modo, inserir informações acerca do capital intelectual nos sistemas de controle de gestão (SCG) de IES é sinônimo de uma necessidade implicitamente declarada nos resultados da pesquisa de Widener (2004).

Outrossim, tal contexto converge com os trabalhos seminais de Burns e Stalker (1961) e Chandler (1962) sobre a Teoria da Contingência. Tal abordagem teórica estuda o impacto das mudanças ambientais nas organizações, bem como a respectiva adaptação da estrutura organizacional, com a adoção de controles gerenciais, diante de tais vicissitudes ou fatores contingenciais.

A partir desse enredo, este ensaio teórico propõe uma discussão sobre a possibilidade da formação de capital intelectual em instituições de ensino superior influenciar a forma como se constituem os sistemas de controle gerenciais, em razão da crescente discussão sobre os reflexos desse capital no desempenho das organizações. Deste modo, a seguinte pergunta de pesquisa é levantada: sistemas de controle de gestão das instituições de ensino superior públicas são afetados pela existência de capital intelectual?

A questão da pesquisa, exposta no parágrafo acima direciona o objetivo central do presente ensaio teórico, que consiste em discutir a influência do capital intelectual nos sistemas de controle de gestão de universidades públicas, sob a perspectiva do capital intelectual como fator contingencial. $\mathrm{O}$ objetivo geral desdobra-se nos seguintes objetivos específicos: a) apontar o capital intelectual como um fator de melhor desempenho frente as contingencias e que afeta os controles gerenciais de IES públicas; b) relatar se o controle do recurso capital intelectual é efetivamente realizado pelas IES públicas; e c) refletir sobre a relevância de integrar as informações acerca do capital intelectual nos SCG de universidades públicas.

A presente discussão justifica-se pela busca de uma compreensão mais clara acerca da forma com que as universidades públicas gerenciam o capital intelectual, recurso determinante para o alcance da missão de tais instituições e para o enfrentamento das contingências. A escassez de trabalhos científicos sobre o cenário ora exposto contribui para a relevância da presente discussão. Encontraram-se apenas 11 trabalhos nas bases de dados nacionais (portal da Capes e Spell) relacionados com as palavras-chave capital intelectual e controle - resultados voltados para a temática de contabilidade gerencial. Contudo, nenhum dos trabalhos dispensa atenção ao setor público.

Ademais, Córcoles e Ponce (2013) afirmam que as pesquisas sobre a temática do capital intelectual em instituições de ensino superior são de vital importância, principalmente devido o conhecimento ser a principal input (entrada) e output (saída) nessas instituições. Além disso, a crescente preocupação social sobre o estabelecimento de procedimentos para prestação de contas que assegurem a transparência das informações nas universidades públicas tem levado a necessidade de divulgar informações sobre o seu capital intelectual (Córcoles, Ponce, 2013).

No Brasil, pesquisas que tratam do capital intelectual como fator para fazer frente as contingências ambientais são inexistentes. Assim, é imperativo o desenvolvimento deste campo de investigação, principalmente por sua utilidade potencial para a melhoria das instituições de ensino superior IES, que sugerem depender em potencial da geração de capital intelectual como fonte de criação de valor. Estudos sugerem que as contingências podem ser minimizadas pelos sistemas de controles gerenciais a fim de minimizar o efeito das variáveis ambientais sobre as organizações (Hayes, 1976).

As finalidades da educação superior, previstas na Lei Brasileira de Diretrizes e Bases, têm uma ligação com a era do conhecimento, pois objetiva formar profissionais para participação do desenvolvimento social. Por duas razões essas organizações são relevantes nesse estudo. A primeira por tratar-se de instituição de ensino, fomentadora do conhecimento, que estimula o pensamento crítico e a iniciação científica. Em segundo lugar, por ser uma organização detentora de proporções expressivas de capital humano. 
Córcoles e Ponce (2013) investigaram as principais razões pelas quais as universidades espanholas não divulgam informações sobre o seu capital intelectual no modelo de informações contábeis e as consequências positivas que podem resultar de tal divulgação. Os resultados obtidos mostraram que a divulgação de capital intelectual propicia uma maior transparência à instituição, um aumento da satisfação do usuário e melhor credibilidade, imagem e reputação da universidade, ao mesmo tempo que é a falta de sistemas internos de identificação e mensuração dos elementos intangíveis foi a principal razão para as universidades não divulgarem as informações sobre o capital intelectual.

Nesta perspectiva, mais pesquisas são necessárias para ampliar o conhecimento de como o capital intelectual pode contribuir para reduzir contingências. Desse modo, a relevância desta pesquisa está em contribuir para o desenvolvimento deste campo de pesquisa na perspectiva contábil, ao abordar aspectos da formação do capital intelectual sob a luz da Teoria da Contingência. Expande-se, portanto, o campo de estudos organizacionais em contabilidade, ao investigar esse tema em instituições de ensino público.

\section{FUNDAMENTAÇÃO TEÓRICA}

\subsection{Capital Intelectual}

Os conceitos capital humano $(\mathrm{CH})$ e capital intelectual $(\mathrm{CI})$ com frequência são confundidos em razão de estarem envolvidos com o conhecimento. No entanto simplificadamente define-se que o capital humano é um componente do capital intelectual, ou seja, a soma de $\mathrm{CH}$ a outros elementos como capital relacional, por exemplo, será igual ao CI.

Em primeiro lugar, os membros da organização possuem conhecimento tácito individual que são habilidades inarticuláveis necessárias para desempenhar as suas funções (Nelson \& Winter, 2009). Quando esse conhecimento é especifico e de difícil imitação, e tem uma forte relação com a missão, ele se converge em capital humano.

O Capital Intelectual é considerado como o total de ativos intangíveis e tomou força na era do conhecimento, com a mudança do paradigma da economia com base no capital para a economia da inovação, baseada no conhecimento (Bontis, 1998).

De acordo com Calix, Vigier e Briozzo (2015) o capital intelectual é definido como um material intelectual, por exemplo, conhecimento, informação, propriedade intelectual, experiência, que pode ser usado para criar valor. É a inteligência coletiva, é difícil identificar e distribuir de forma mais eficiente, mas que se encontra e explora vantagens dentro das organizações. $\mathrm{O}$ capital intelectual abrange não somente o capital humano, produzido internamente pelas e nas organizações, mas também sua estrutura e relações externas. O capital intelectual é mais abrangente que somente observar a empresa sob a ótica da criação de valor promovido pelo conhecimento humano.

Portanto, o ativo intangível de uma organização é composto por capital humano, ou seja, habilidades, talento e conhecimento; por capital da informação ou estrutural, ou seja, bases de dados, sistemas de informação e infraestrutura tecnológica; e pelo capital organizacional ou relacional, ou seja, a cultura, estilo de liderança, capacidade de compartilhar conhecimento e relacionamentos externos à empresa, tais como os clientes e fornecedores (Bontis, 1998; Kaplan \& Norton, 2004).

Bontis (1998) afirma que a nova economia se desenvolveu a partir da concorrência global e o predomínio do capital intelectual. Em ambientes com ampla concorrência algumas características como aprendizado contínuo e formalização do conhecimento tornam-se necessárias, em razão das mudanças dinâmicas do ambiente institucional. Essas mudanças tornam a capacidade de adaptação fundamental para se obter vantagem competitiva. Neste cenário, a organização é impulsionada a inovar e a criar valor. Subramaniam e Youndt (2005) afirmam que essa capacidade tem forte relação com o capital intelectual da organização. Uma vez que os recursos de natureza intangível são reconhecidos como o mais importante para alcançar os objetivos das organizações (Romero, 2016).

Dierickx e Cool (1989) definem que capital intelectual é o estoque de conhecimento na empresa. Mas como guardar esse estoque? Como quantificar o estoque? O capital intelectual tem sido estudado, mas em relação à sua compreensão pouco se evidencia, principalmente por parte dos gestores. Para Bushfield (2008) gestores e investidores negligenciam entradas e saídas intelectuais, mesmo que, em geral, percebam a importância do capital intangível e inclusive o quanto ele representa no valor da empresa. A mesma autora destaca a definição de que o capital intelectual é como o material intelectual, conhecimento, informação, propriedade intelectual, experiência, porém delimita como aquilo que pode ser aproveitado para criar riqueza. Há similaridade na definição de capital intelectual e no reconhecimento da dificuldade para medi-lo.

Este intangível indescritível não pode ser avaliado em termos financeiros habitualmente utilizados (Bontis, 1998). No entanto, seu impacto nos controles tradicionais não tem sido objeto de questionamento, não atingindo consenso nem mesmo no setor privado. Contudo, nas organizações tem-se utilizado de mecanismos de medição, tais como: Skandia's Navigator, VAIC (Valor Acrescentado de Coeficiente Intelectual) e IC-Index (Bushfield, 2008). Esses instrumentos visam de uma forma ou de outra mensurar qualitativamente para transformar em algo quantificável que possa ser objeto gerador de valores financeiros. 
As organizações que buscam medir o capital intelectual buscam melhores resultados financeiros. De modo geral, o valor contábil é superado em várias vezes pelo valor intangível, que é reflexo do capital intelectual. Se ele é tão representativo nada mais natural do que monitorá-lo com a ênfase que a proporção requer. Porém, refletindo sobre o assunto, percebe-se que nenhuma empresa deixaria seu dinheiro, espaço na fábrica ou estoque ociosos, mas em relação ao conhecimento não se observa uma preocupação nesse quesito. Pode-se definir que o conhecimento que os funcionários possuem, a opinião dos clientes, as regras, a missão, entre outros, quando não utilizados são, em tese, equivalentes a recursos financeiros desperdiçados.

As empresas evidenciam esses ativos para alavancar seu próprio valor. Bontis (1998) ensina que as empresas não negociam seus ativos intangíveis. $\mathrm{O}$ estoque de capital humano, o fluxo de conhecimento e aprendizado organizacional não pode ser valorado como os ativos tangíveis. Não existe uma formula exata do valor do intangível; às vezes, são atribuídos valores sem quaisquer existências de transações monetárias. No Quadro 1 apresentam-se as definições e conceitos sobre o tema.

Quadro 1 - Definições selecionadas do Capital Intelectual (Ativos Intangíveis)

\begin{tabular}{|c|c|}
\hline DEFINIÇÕES & AUTORES \\
\hline $\begin{array}{l}\text { - O material intelectual - conhecimento, informação, propriedade intelectual, experiência - que pode } \\
\text { ser aproveitado para criar riqueza. }\end{array}$ & Stewart (1998) \\
\hline - Recursos específicos da empresa que são indispensáveis para criar valor a ela. & $\begin{array}{l}\text { Nonaka et al. } \\
\quad(2000)\end{array}$ \\
\hline $\begin{array}{l}\text { - Valor econômico gerado por duas categorias de ativos intangíveis de uma empresa: capital } \\
\text { organizacional e capital humano. }\end{array}$ & OCDE (2000) \\
\hline $\begin{array}{l}\text { - Ativos intangíveis são fontes não físicas de valor (pedidos de benefícios futuros) gerados pela } \\
\text { inovação (descoberta); modelos organizacionais exclusivos ou práticas de recursos humanos. }\end{array}$ & Lev (2001) \\
\hline $\begin{array}{l}\text { - O grupo de ativos de conhecimento que são atribuídos a uma organização e contribuem mais } \\
\text { significativamente para a melhoria da posição competitiva desta organização, agregando valor às } \\
\text { principais partes interessadas definidas. Incluem ativos humanos, ativos de relacionamento, ativos } \\
\text { de cultura, práticas e rotinas, ativos intelectuais de propriedade e ativos físicos. }\end{array}$ & $\begin{array}{l}\text { Marr e Schiuma } \\
\qquad(2001)\end{array}$ \\
\hline $\begin{array}{l}\text { - O capital intelectual de uma empresa/instituição abrange o capital humano, estrutural e relacional. } \\
\text { Como toda inovação vem do intelecto ou conjunto de conhecimento dos seres humanos, é evidente } \\
\text { que o capital intelectual é originado do capital humano. }\end{array}$ & Johnson (2002) \\
\hline $\begin{array}{l}\text { - Capital Humano consiste no capital intelectual, social e emocional de indivíduos e organizações. O } \\
\text { capital intelectual refere-se a atributos individuais fundamentais tais como complexidade cognitiva e } \\
\text { a capacidade de aprender, em conjunto com o conhecimento tácito e explícito, habilidades e } \\
\text { competências que um indivíduo constrói ao longo do tempo. }\end{array}$ & $\begin{array}{c}\text { Gratton e } \\
\text { Ghoshal (2003) }\end{array}$ \\
\hline $\begin{array}{l}\text { - Ativos intangíveis consistem em capital humano, ou seja, habilidades, talento e conhecimento; } \\
\text { capital da informação, ou seja, bases de dados, sistemas de informação e infraestrutura tecnológica; } \\
\text { e capital organizacional, ou seja, a cultura, estilo de liderança, capacidade de compartilhar } \\
\text { conhecimento. }\end{array}$ & $\begin{array}{l}\text { Kaplan e Norton } \\
\qquad(2004)\end{array}$ \\
\hline $\begin{array}{l}\text { - A soma de todos os conhecimentos da empresa usados para vantagem competitiva - três fatores } \\
\text { proeminentes: humano, organizacional e capital social. }\end{array}$ & $\begin{array}{l}\text { Subramaniam e } \\
\text { Youndt (2005) }\end{array}$ \\
\hline $\begin{array}{l}\text { - Capacidade técnica de seu corpo de funcionários em gerar benefícios futuros denominados de } \\
\text { Capital Intelectual. }\end{array}$ & $\begin{array}{l}\text { Bonacim et al. } \\
\quad(2010)\end{array}$ \\
\hline
\end{tabular}

Fonte: Adaptado de Bushfield (2008).

O Quadro 1 mostra as principais definições do que é capital intelectual. Para evitar interpretações criativas Bontis (2008) define que capital intelectual não inclui propriedade intelectual. Na propriedade intelectual estão os ativos: direitos autorais, patentes, marcas de comércio e serviços, entre outros.
Diversos pesquisadores concordam que existem três elementos que compõem o capital intelectual: capital humano, capital organizacional (ou estrutural) e social (relacional) (Bontis, 1998; Johnson 2002; Subramaniam \& Youndt, 2005). Há um consenso em relação à definição de que o capital humano é um elemento do capital intelectual, que interage 
constantemente com os outros componentes do CI para gerar vantagem competitiva.

O capital humano é importante porque constitui fonte de inovação e renovação estratégica. Pode ser medido, porém não é uma tarefa fácil (Bontis, 1998). As organizações, principalmente as competitivas, necessitam medir se seus objetivos estão sendo atingidos. A partir desta demanda, surgem ferramentas no intuito de superar as tradicionais medidas financeiras como principais direcionadores da tomada de decisão. A abordagem denominada Balanced Scorecard (BSC), idealizada por Kaplan e Norton (1998), é amplamente utilizada no meio empresarial.

Por fim, o capital humano, somado às relações sociais e conhecimento formal, compõe os ativos intangíveis. Esses ativos geram inquietações quando colocados ao lado do valor de mercado de empresas que participam em mercados de capitais. É notável que as empresas, em geral, desejam aumentar seus ativos intangíveis. Porém, esse desafio parece ainda percorrer um longo caminho.

\subsection{Instituições públicas de ensino superior}

Antes de prosseguir, conceitua-se instituição pública. Tais instituições são criadas para atender uma finalidade pública, ou seja, prestar serviços para sociedade. Nesse sentido, as instituições públicas nascem com valores e crenças pré-existentes na sociedade e sobrevivem enquanto eles perdurarem. Uma instituição pública que não atinge sua finalidade não tem razão de existir. Como organização, para atingir seus objetivos, precisam adotar as mesmas técnicas, princípios e modelos organizacionais das instituições de natureza privada.

Bushfield (2008) mostra que a criação de valor público é um elemento-chave da política pública moderna. Mas o que é valor público? Moore (2003) ensina, em seu texto seminal, que versa sobre criação de valor público, que gestores públicos devem buscar produzi-lo. Estudos sobre o tema dividem-se em dois grupos: os que defendem valor público como um meio de gestão do setor público e aqueles que consideram a relação entre o valor público e medição de desempenho (Bushfield, 2008). Mas esse valor público é o ativo intangível?

No entanto, afirma-se que as técnicas habitualmente utilizadas nas empresas privadas não são aplicáveis ao setor público, e nesse caso o ativo intangível mensurado pela diferença entre o capital total investido na empresa e seu valor de mercado não é útil como parâmetro no setor público (Stoker, 2006). Por outro lado, não há recomendações sobre como proceder. As instituições precisam melhorar a comunicação, inovar a gestão e buscar a legitimidade, mas os meios utilizados e frequentemente objetos de pesquisa, são em grande parte da área privada. Sendo assim é de relevância discutir as práticas administrativas das organizações públicas, pois a sociedade voltada ao conhecimento pode não legitimar administrações ineficientes (Bushfield, 2008).

Diante da era do conhecimento e da percepção da importância do capital intelectual para competitividade, levanta-se a questão: que tipo de valor tem o capital intelectual em instituições públicas? Pois se a mensuração financeira conta com a diferença entre o valor da empresa e o total de ativos tangíveis, no sistema público isso não é possível. Porém, isso não implica em descartar o controle e desenvolvimento desse ativo intangível, pois se a razão da percepção de valor da empresa privada é a expectativa de ganhos futuros no setor público é desejável que se proporcione a mesma expectativa de maior valor público.

Córcoles e Ponce (2013) afirmam que uma das principais iniciativas relacionadas com a preparação e elaboração de relatórios de capital intelectual nas instituições de ensino superior foi desenvolvida pelas universidades austríacas. Desde 2007, eles são obrigados a apresentar Capital Intelectual Reports. Nesse relatório, as universidades devem incluir, no mínimo, os seguintes elementos: as atividades da Universidade, metas e estratégias sociais e voluntárias; seu capital intelectual dividido em capital humano, estrutural e relacional; apresentação do desempenho processual incluindo os seus resultados e impactos. A Figura 1 mostra a estrutura básica desse relatório. 
Figura 1 - Modelo capital intelectual para as universidades austríacas.

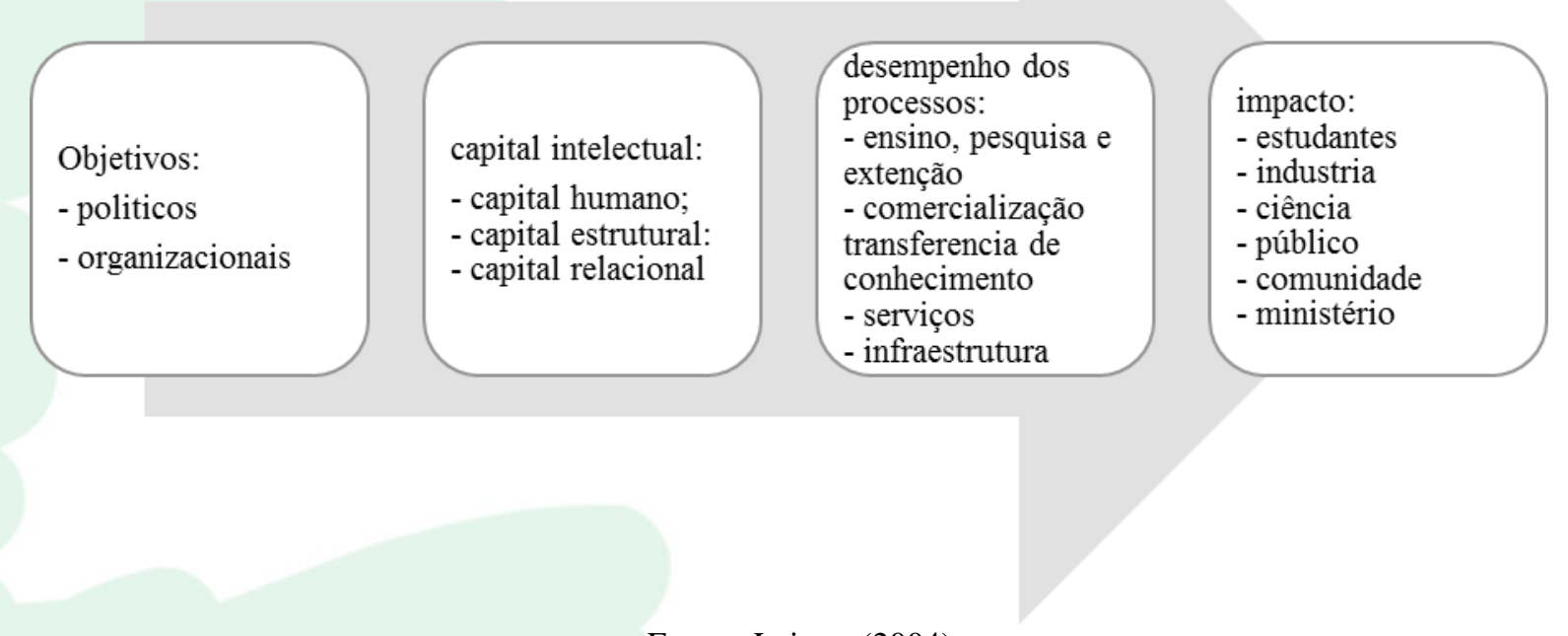

Fonte - Leitner (2004)

No Brasil, a normativa contábil vigente restringe o reconhecimento de intangíveis. $\mathrm{O}$ que pode ser observado no website do Ministério do Planejamento, Orçamento e Gestão e Secretaria do Tesouro Nacional, que elabora e divulga o Manual de Contabilidade Aplicada ao Setor Público, que está em sua sexta edição. Somente os ativos intangíveis adquiridos podem ser refletidos no balanço de uma organização, situação que limita o controle e o enfoque dado nesse elemento de capital.

Segundo Córcoles e Ponce (2013) por esta razão, existem inúmeras organizações, entidades e acadêmicos que ciente da dificuldade de incorporar o capital intelectual com as regras atuais, tendem a recomendar o desenvolvimento e apresentação de Capital Intelectual Reports de maneira voluntária, uma vez que admitem que os relatórios sobre o capital intelectual contêm um conjunto de indicadores que contribuem para melhorar a qualidade das informações contábeis para as organizações.

No entanto o descaso com a CI não aparente ocorrer com treinamento. O Decreto 5.707/06 é um exemplo de reflexo da percepção da importância do conhecimento, pois traz diretrizes sobre $o$ desenvolvimento de competências individuais visando o desenvolvimento de competências institucionais. Por outro lado, destaca-se que a CI é pouco discutida no âmbito contábil, mas é possível observar informações de controle externo nos portais do Tribunal de Contas da União (TCU, 2015) e da Controladoria Geral da União (CGU, 2015), denominados relatórios de gestão, de todas instituições públicas federais. Destaca-se que os relatórios das IFES poderiam ser utilizados como um controle de CI no entanto não foram evidenciadas orientações legais sobre esse tema.

As organizações do setor público operam em ambientes tão complexos e dinâmicos quanto as instituições privadas. Porém, as instituições privadas têm como reflexo da comparação com o ambiente competitivo a constante necessidade de adaptações e melhorias continuas em busca de processos mais eficientes que possibilitem a sua permanência no mercado. Mas como estimular o comportamento que se evidencia na ampla concorrência do mercado? É função do gestor público gerenciar com a finalidade de garantir que os objetivos da instituição sejam relevantes e legítimos, e podem ser alcançados de forma eficaz e eficiente (Bushfield, 2008). Essa relação com o setor privado - que tem a eficiência como condição de sobrevivência - e o setor público - que a utiliza apenas como um ideal de gestão - é que permeia a discussão deste artigo.

Nesse contexto, o capital intelectual pode ser representado também na área pública. Os resultados dessa relação se refletem como valor público, mas nem sempre esse valor é fácil de quantificar. Diversos estudos sugerem medidas de desempenho, como por exemplo o "valor público scorecard" de Moore (2003). É possível questionar: No setor público o capital intelectual deveria ser medido? As consequências dos investimentos em capital humano poderiam ser objeto de estudos sistemáticos antes que o gestor público tomasse a decisão sobre o direcionamento desse capital? Essas talvez sejam as perguntas que todo 
gestor público deveria fazer antes da escolha entre os investimentos que visam gerar valor público e legitimar a instituição.

\subsection{Teoria da Contingência}

De modo geral, as organizações são fortemente dependentes do ambiente no qual estão inseridas; a mudança é inerente ao ambiente, o que afeta as organizações e a forma como se estruturam (Hayes, 1976). A Teoria da Contingência (TC) estuda os elementos de mudança, fatores externos, ambientais, ou seja, as variáveis que afetam a estrutura das organizações. A ideia de uma teoria da contingência aplicada a contabilidade gerencial começou a se desenvolver na década de 1970, numa tentativa de explicar as variedades de práticas de contabilidade gerencial que eram evidentes naquele momento (Otley, 2016).

A capacidade de adaptação organizacional é o essencial e Hayes (1976) adverte em seu trabalho a urgência de se utilizar controles gerenciais a fim de minimizar o efeito das vaiáveis ambientais sobre as empresas.

Não existe nada de absoluto nas organizações, o the best way pregado pela teoria administrativa clássica não tem lugar no mundo real, pois tudo é relativo
(Junqueira, 2010). Esta abordagem teórica prioriza a adaptabilidade, pois o ambiente é um fator determinante para as práticas organizacionais sistemas de controle gerencial e consequente desempenho, por exemplo. Deste modo, diante de uma determinada situação ambiental, é natural que as empresas reajam com vistas para a eficiência, tendo em vista o êxito de suas operações.

Inicialmente, o foco da abordagem contingencial era o ambiente e a tecnologia como variáveis ambientais, ao passo que apenas a partir de 1970 estudos acerca da estrutura organizacional, e, consequentemente, o sistema de controle gerencial passaram a ser estudados (Camacho, 2010). Marques (2012) enumera os fatores contingentes como ambiente, estratégia, porte, estrutura e tecnologia. Fatores internos e externos às organizações influenciam nas práticas gerenciais, conforme representado no Quadro 2:

O Quadro 2 mostra que as instituições de ensino superior admitem, em termos de estrutura organizacional, características mecânicas ou orgânicas, conforme os fatores específicos divisão do trabalho, especialização do trabalho, padronização das atividades, centralização e processo decisório e ambiente organizacional, conforme a pesquisa de Fagundes et al. (2008).

Quadro 2 - Estruturas organizacionais em instituições de ensino superior

\begin{tabular}{|c|c|c|}
\hline Fatores & Estrutura mecânica & Estrutura orgânica \\
\hline Divisão do trabalho & $\begin{array}{l}\text { Minuciosa divisão do trabalho - estruturas } \\
\text { burocráticas, detalhistas }\end{array}$ & $\begin{array}{l}\text { Estruturas flexíveis, nem sempre sujeitas à } \\
\text { divisão do trabalho e à fragmentação }\end{array}$ \\
\hline $\begin{array}{l}\text { Especialização do } \\
\text { trabalho }\end{array}$ & $\begin{array}{c}\text { Elevada: divisão do trabalho e fragmentação } \\
\text { das tarefas possibilita a criação de cargos } \\
\text { ocupados por especialistas, com atribuições } \\
\text { bem definidas. }\end{array}$ & $\begin{array}{l}\text { Baixa: cargos generalistas continuamente } \\
\text { redefinidos por interação com outros } \\
\text { indivíduos participantes da tarefa. }\end{array}$ \\
\hline $\begin{array}{l}\text { Padronização das } \\
\text { atividades }\end{array}$ & Elevada: atividades rotineiras e estáveis & Baixa: atividades inovadoras/ não- estáveis \\
\hline $\begin{array}{c}\text { Centralização e } \\
\text { processo decisório }\end{array}$ & \begin{tabular}{|} 
Alto grau de centralização. Decisões \\
geralmente reservadas à cúpula organizacional. \\
Pouca delegação \\
Grande complexidade vertical (grande número \\
de níveis hierárquicos) e horizontal (cargos e \\
departamentos)
\end{tabular} & $\begin{array}{c}\text { Descentralização do processo decisório, } \\
\text { delegação e responsabilidade compartilhada } \\
\text { Baixa complexidade vertical (poucos níveis } \\
\text { hierárquicos) e horizontal }\end{array}$ \\
\hline $\begin{array}{l}\text { Ambiente } \\
\text { organizacional. }\end{array}$ & $\begin{array}{l}\text { Estável: permanecem constantes durante o } \\
\text { tempo, mudanças lentas }\end{array}$ & Instável: mudanças abruptas e constantes \\
\hline
\end{tabular}

Fonte: Adaptado de Fagundes et al., (2008, p. 10).

A teoria da contingência orienta a busca por uma estrutura organizacional otimizada diante fatores internos e ao ambiente externo à organização, o qual também influencia internamente as organizações (Hayes, 1977; Waterhouse e Tiessen, 1978; Marques, 2012). Assim, o Quadro 2 ilustra as variáveis contingenciais relacionadas à estrutura organizacional, observáveis em IES públicas. Tal situação é compatível com os achados de Guerreiro, Pereira e Rezende (2008), os quais afirmam que os aspectos estruturais determinam os sistemas de controle gerencial que melhor se encaixam a uma dada organização.

O estudo de Chenhall (2003) faz uma revisão sobre estudos dessa teoria desde 1980, indicando urgência de trabalhos futuros com abordagem qualitativa. Adicionalmente Hall, (2016) afirma que a 
Teoria da contingência utilizada na pesquisa em contabilidade gerencial é uma abordagem que busca compreender como o funcionamento e os efeitos das práticas de contabilidade gerencial não são universais e dependem dos diferentes contextos nos quais essas práticas operam. Portanto, dentro da abordagem gerencial, a teoria da contingencia pode ser utilizada para proporcionar predições e/ou explicações esperadas, e/ou caracterizar as relações observadas, associadas a outras teorias tais como as teorias de economia, psicologia ou sociologia.

Nesse contexto, torna-se relevante dar atenção para o fator capital intelectual e sua interação com nas organizações. A contribuição pretendida com este trabalho é discutir a variável capital intelectual e sua influência nos sistemas de controle de gestão, nas ferramentas que promovem a adaptação da organização das IES públicas. Uma vez que, a premissa da teoria da contingência é que os sistemas de controle diferem entre organizações com base em fatores organizacionais subjacentes (Esta abordagem teórica permite o desenvolvimento dos sistemas de gestão diante de contingências específicas, o que possibilita ao gestor conduzir a organização para melhores resultados (Beuren \& Macohon, 2011).

\section{DELINEAMENTO METODOLÓGICO}

Esta pesquisa tem como objetivo investigar novas perspectivas do tema; quanto aos procedimentos, realizou-se principalmente pesquisa bibliográfica e documental (Raupp \& Beuren, 2009).

Embora não exista uma metodologia que se encaixe perfeitamente, é exatamente esse o foco de um ensaio teórico (Meneghetti, 2011). Nele se discute a relação entre um tema em evidência no contexto organizacional (capital intelectual e teoria da contingencia) e um possível sujeito (instituições públicas) da percepção desse tema. A relação entre o sujeito e o objeto construída através da subjetividade (influência do capital intelectual) e objetividade (sistemas de controle) em cada elemento da discussão busca-se conduzir os entre laços. Torna-se essa modalidade uma referência para autores que se posicionam de forma crítica sobre determinados fenômenos. Bertero (2011) considera que os sentimentos, incertezas e contradições de uma pessoa merecem divulgação, o que motiva um pensamento livre e a disposição dos argumentos sem as regras metodológicas rígidas, comuns nas ciências naturais.

Nessa perspectiva, foram realizadas buscas no portal de periódicos da CAPES, com as seguintes palavras chaves: capital intelectual, capital humano, sistema de controle, controles gerenciais, controles de pessoas, controles contábeis, controle contábil, gestão. Para viabilizar um filtro adequado realizou-se combinações sistemáticas entre os termos capital humano ou capital intelectual, um cruzamento com as palavras que indicam controle, verificando que, os artigos encontrados possuíam, além dos temas principais, também a palavra que indicasse controle ou gestão. Esse formato de busca acabou evidenciando apenas 19 artigos. Após esse filtro busca-se na leitura dos artigos estudos que avaliassem o capital intelectual em instituições públicas de ensino superior, no entanto não obteve-se êxito. Por essa razão utilizou-se também a indicação de pesquisadores de contabilidade. Após a leitura dos artigos, foram ainda levantadas as obras dos autores mais citados do tema capital intelectual, principalmente estudos direcionados a área pública, possibilitando uma avaliação crítica. Para tornar os argumentos mais sólidos revisou-se os manuais de contabilidade do Governo Federal e a Lei de Diretrizes e Bases.

Cuidou-se da origem dos fundamentos, porém libertou-se na abstração e intenção de motivar outras conclusões. O sentido do ensaio teórico não está na formulação de respostas verdadeiras, mas no surgimento de problemáticas e perguntas a serem respondidas, impulsionando o leitor ao pensamento crítico (Meneghetti, 2011).

\section{DISCUSSÃO}

O foco deste estudo é discutir se sistemas de controle de gestão das instituições de ensino superior públicas são afetados pela existência de capital intelectual, e percebe-se que no setor público, especialmente as universidades dão os primeiros passos nesse "novo caminho".

García-Ayuso (2003) relata que os ativos intangíveis são fontes fundamentais de vantagem competitiva sustentável e devem ser identificados, medidos e controlados, a fim de assegurar a gestão eficaz e eficiente das organizações. Stefano et al. (2014) ensinam que existe uma relação entre investimentos em intangíveis, ganhos subsequentes e geração de valor, o que vai ao encontro com a necessidade de medir e controlar esses investimentos. Os autores afirmam, ainda, que tal recurso afeta positivamente o desempenho de uma organização no mercado. Essa linha de raciocínio delimita a perspectiva do primeiro objetivo específico que é: a) apontar o capital intelectual como um fator de melhor desempenho frente as contingencias e que afeta os controles gerenciais de IES públicas.

Ao comparar os recursos tangíveis e intangíveis e seus respectivos controles, percebe-se que o controle sobre o conhecimento é pouco noticiado pelos órgãos públicos. No caso do orçamento, as instituições publicam anualmente a lei orçamentária que desencadeia uma série de ações que são amplamente monitoradas e frequentemente noticiadas inclusive por veículos de massa; mas e os indicadores de desempenho não financeiro, onde são tornados públicos?

Se por um lado os gestores buscam gerenciar cada componente da organização, calculando retorno, 
espaço, tempo, ociosidade quase que automaticamente, num ciclo há tempos consolidado. Por outro lado, embora lembrado com frequência, o capital intelectual é abordado de forma superficial, tanto em organizações privadas e públicas (Bontis, 1998). O que isso significa? Estudos revelam um reflexo positivo do capital intelectual no desempenho da empresa (Bontis, 1998; Widener, 2004). De outro modo, as discussões não abordam se há um limite nesse impacto, ou seja, se há um ponto em que o aumento em investimentos em capital intelectual não impactará no desempenho, principalmente na prestação de serviços públicos.

A mudança no paradigma econômico em que o conhecimento é valorizado em busca da gestão eficiente afeta o setor público, pois trata-se da mesma sociedade que transita entre os serviços e bens públicos e privados. A partir da percepção da relevância do capital intelectual, bem como de seu respectivo reflexo em empresas privadas, uma consequência natural seria a exigência de que comece a se pensar como esse capital intelectual está inserido no setor público. Mas como o capital intelectual afeta as práticas administrativas e, por consequência, os controles gerenciais de IES públicas, visto que tais instituições possuem elevado volume de capital humano? O Quadro 1 mostra, sucintamente, a definição de capital intelectual, que consiste em recurso de conhecimento utilizado para gerar riqueza e vantagem competitiva.

Uma das diferenças entre o setor privado e o setor público é a geração de riqueza ou valor. Na área pública as instituições não têm valor no mercado. Em contrapartida, a sociedade precisa de novas soluções, melhores serviços, otimização de resultados e racionalização de recursos financeiros. Nesse sentido, a necessidade de capital intelectual e a participação deste recurso na gestão pública acaba despertando o interesse social. Esse interesse é expressado por meio de leis e decretos, como exemplo o art. $5^{\circ}$ do Decreto 5.707 de fevereiro de 2006, que institui diretrizes para a carreira pública federal, que delega à Secretaria de Gestão do Ministério do Planejamento a competência do desenvolvimento e a implementação de sistema de gestão por competência.

Com a criação das diretrizes legais, passa-se a ter um controle sobre ações relacionadas a capital humano por meio dos órgãos de controle, que na área pública têm independência em relação à gestão. Todavia, como o controle sobre esse capital intelectual funciona na área pública, é um interessante tema de pesquisa, pois a lei traz algumas diretrizes de capacitação, gestão por competência, e desenvolvimento contínuo, mas não delimita como gerenciar o capital intelectual, ou mesmo o capital humano. Outra diferença do setor público está na construção dos controles financeiros e gerenciais. As instituições públicas são constantemente monitoradas pelas auditorias internas, externas e tribunais de contas, os controles acabam se limitando ao atendimento das demandas produzidas por esses órgãos. Partindo dessas premissas que tecemos alguns apontamentos sobre o segundo objetivo: b) relatar se o controle do recurso capital intelectual é efetivamente realizado pelas IES públicas.

Em busca de informações de controle externo nos portais do Tribunal de Contas da União (TCU, 2015) e da Controladoria Geral da União (CGU, 2015), encontraram-se apenas os relatórios de gestão, usualmente solicitados para tomadas de contas especiais. Esse relatório tem um escopo padronizado que contempla a estrutura de pessoas (número de terceirizados, professores por aluno, servidores por aluno). Não foi evidenciado nenhum indicador de desempenho com relação com gestão de capital intelectual. Porém o relatório tem campos abertos que permitem que as instituições coloquem aspectos diferentes da gestão, uma análise qualitativa desses relatórios poderia conduzir a um esclarecimento sobre como as instituições federais, podem gerir o capital intangível. Cabe esclarecer que a discussão é sobre os sistemas de gestão e controle de intangíveis das instituições como um todo, pois os controles que não foram tornados públicos ou monitorados pelos órgãos externos são justamente o tema da discussão proposta.

No setor público há uma concepção de quanto mais desenvolvimento no capital humano, melhor. Os concursos públicos são um exemplo de seleção em busca dos profissionais mais qualificados, e medem, em geral, competências lógico-matemáticas, linguística e, eventualmente, questões técnicas ou habilidades. Após a entrada no serviço público, há o desenvolvimento profissional por meio das carreiras, que são progressivas e escalares. Todo servidor racionalmente pode capacitar-se ou adquirir conhecimento para atingir melhores salários subindo de nível nessa carreira.

No caso do Governo Federal o servidor deve desenvolver competências na área de conhecimento do seu ambiente organizacional para alcançar melhorias financeiras. A crítica sobre esse sistema é que, em geral, o capital humano se desenvolve apenas em razão dos incentivos econômicos já que todos têm os mesmos direitos, não há disputa, mas apenas uma escalada contínua. O Decreto 5.707/06 é um exemplo de reflexo da percepção da importância do conhecimento, pois traz diretrizes sobre o desenvolvimento de competências individuais visando o desenvolvimento de competências institucionais. Porém, é preciso evidências empíricas para identificar se isso ocorre na prática.

Uma oportunidade de pesquisa é verificar como as instituições planejaram atingir essa competência institucional que poderia ser interpretada como capital intelectual, buscando identificar se existe um controle sobre o resultado desse desenvolvimento. Destaca-se que o enfoque estabelecido neste artigo é o capital intelectual como ativo intangível objeto de controle da contabilidade e não a temática gestão do conhecimento. Portanto o foco é entender o quanto dele é controlado com objetivo de gerar valor público, ou melhor desempenho. 
Enfim, formula-se a seguinte observação:

P1 - As instituições públicas, planejam atingir competência institucional por meio da formação do capital humano, buscando capacitar os indivíduos, no entanto não evidencia-se um sistema de controle gerencial sobre o desempenho do capital humano.

O Governo Federal, por meio principalmente do Ministério do Planejamento, Orçamento e Gestão e Secretaria do Tesouro Nacional, elabora e divulga o Manual de Contabilidade Aplicada ao Setor Público, que está em sua sexta edição. Este documento contém algumas diretrizes sobre os ativos intangíveis. De acordo com o manual, um ativo precisa satisfazer o critério de identificação, ou seja, deve ser separado da entidade e vendido, ou quando resultar de compromissos obrigatórios. Ele também define que o controle da entidade sobre os eventuais benefícios econômicos futuros ou serviços potenciais gerados pelo pessoal especializado e pelo treinamento é insuficiente para que se enquadrem na definição de ativo intangível, bem como o talento gerencial ou técnico específico, a não ser que esteja protegido por direitos legais. Impõe, ainda, que para reconhecer um intangível é necessário ter prováveis benefícios econômicos ou em serviços futuros e o custo ou valor justo possa ser mensurado com segurança. Outro ponto é não reconhecer o ativo intangível na fase de pesquisa. Isso faz com que o gasto, relativo as pesquisas, não seja vinculado ao futuro ativo intangível o que pode desestimular o investimento a longo prazo. O rol de exigências para ser reconhecido está direcionado para tecnologias, protótipos e novas ferramentas.

Contudo, por mais que o Governo Federal esboce um primeiro contato com os recursos intangíveis das instituições públicas, esse é um movimento incipiente, ao menos na sua divulgação, pois nesse sentido considera-se que o controle do capital intelectual não é efetivamente realizado pelas IES públicas, pois não são postos à disposição do público, da mesma forma que os controles financeiros. Integrar as informações acerca do capital intelectual, e dos seus reflexos no SCG em universidades públicas é, no mínimo, relevante para a sociedade - usuária do serviço público. Isso se justifica pelo que segue: a) as informações sobre capital humano permitiriam compreender como tal recurso é utilizado, se é retido e repassado; especificamente falando de ensino, a grande massa de capital humano contida no corpo docente das instituições é um campo fértil para pesquisa, também; b) de forma externa, o capital relacional das universidades públicas, principalmente convênios interinstitucionais, são valiosos e merecem ser traduzidos em informações, pois tais cooperações afetam a comunidade; c) as entidades públicas prestam contas à população; o capital estrutural, aqui lembrado (parcialmente) pelos SCG pode ser uma ferramenta útil para a sociedade compreender melhor as ações e papel fundamental que as instituições públicas de ensino superior exercem. Portanto, com base nos estudos sobre capital intelectual como fator de desempenho de Bontis, 1998; Johnson 2002; Subramaniam \& Youndt, 2005, Leitner, 2004 e Córcoles e Ponce (2013) e objetivando suposições sobre o terceiro objetivo específico - c) refletir sobre a relevância de integrar as informações acerca do capital intelectual nos SCG de universidades públicas - formulam-se as seguintes proposições:

P2 - O capital intelectual influencia os sistemas de controle gerencial nas instituições públicas de ensino superior, principalmente em organizações orgânicas (vide Quadro 2).

P3 - O capital intelectual potencializa o desempenho das instituições frente as contingências e, portanto, afeta positivamente os sistemas de controle gerencial nas instituições públicas de ensino superior.

Quanto ao controle, ao que parece contabilmente o estímulo para gestão de ativos intangíveis, do Governo Federal, tem efeito negativo pois impõe muitas barreiras para reconhecê-los. A razão pode ser evitar uma diminuição no patrimônio durante o desenvolvimento desse intangível.

Diante do contextualizado até então, e trazendo à baila o terceiro objetivo - c) refletir sobre a relevância de integrar as informações acerca do capital intelectual nos SCG de universidades públicas - tecemos a discussão final. Como a percepção da importância do capital intelectual se insere nos sistemas de controle de gestão público? Aparentemente para contabilidade do governo federal, o capital intelectual está principalmente ligado à tecnologia e ferramenta, ao desenvolvimento do conhecimento sobre a estratégia, missão, valores da instituição em geral, e por essa razão não precisa fazer parte da contabilidade. Talvez podem ter atribuído essa necessidade de gestão a outras áreas, como por exemplo a de recursos humanos.

Nas instituições públicas de ensino superior pesquisadores enfrentam as mesmas barreiras com relação aos tramites contábeis, porém soma-se a essas os estímulos ligados à pesquisa do setor privado. Se internamente não se tem recursos antes que os intangíveis se convertam em tangíveis, externamente empresas estimulam a pesquisa e desenvolvimento por meio de convênios. Isso pode inclinar racionalmente pesquisadores a manter o foco apenas nas respectivas áreas de conhecimento com estímulos externos. O que acaba distribuindo a produção do conhecimento externamente e tornando ainda mais difícil transformar esse conhecimento em motor para geração de capital intelectual interno, que é reconhecido como importante para atingir os objetivos institucionais.

Portanto considera-se que a influência da orientação estratégica sobre a estrutura organizacional de instituições públicas é cada vez mais necessária. Por 
um longo tempo a literatura sobre os sistemas de controle gerencial foi dominada por uma abordagem universal, o que sugeria que as empresas de alto desempenho precisam usar as melhores práticas disponíveis para superar concorrentes ou manter as quotas de mercado. No entanto, essa abordagem dificilmente se aplica às instituições públicas que são consideradas sem fins lucrativos, operando com os seus próprios limites e ambientes variados.

Espera-se que essas proposições aludidas possam ser testadas e ofereçam suporte para discutir a abordagem contingencial proposta por Hayes (1976), Chenhall (2003), Widener (2004) e Otley (2016) de que as organizações existem em um ambiente de incerteza considerável, em particular, trabalham em um ambiente competitivo do qual há dificuldades em se prever totalmente as contingencias. As instituições também dependem de outras organizações como fornecedores, clientes, prestadores de serviços ou parceiros da rede, e essas relações estão sujeitas a mudanças em curso.

O ambiente econômico global é cada vez mais imprevisível, portanto nenhum setor está imune a mudanças que acontecem a longo prazo. Mesmo o setor público está sujeito a algumas dessas características e também pelos caprichos da política pública, portanto as mudanças às vezes podem ser bastante imprevisíveis o que torna fundamental o controle do capital intelectual e seus efeitos nos sistemas gerenciais. Além disso, o ambiente organizacional interno também está sujeito a incertezas consideráveis sobre como os funcionários irão se comunicar, coordenar e geralmente se comportam de maneira favorável para produzirem operações eficientes (Otley, 2016). Seja internamente ou externamente as instituições precisam ser monitoradas. O CI afeta o desempenho e por sua vez a forma como se constituem as práticas administrativas. Destarte, conclui-se que é relevante integrar as informações acerca do CI nos SCG.

\section{CONSIDERAÇÕES FINAIS}

Finalmente, é perceptível que as regras no setor público são segregadas, ou seja, há exigência de desenvolvimento de competência institucional, mas não há reconhecimento contábil da parcela intangível dos recursos das IES públicas. Na área privada isso dificilmente ocorreria, em razão da expectativa da possibilidade desse capital intelectual gerar valor na empresa.

Quanto à pergunta de pesquisa, sistemas de controle de gestão das instituições de ensino superior públicas são afetados pela existência de capital intelectual? Conclui-se que a presença de capital intelectual no setor público influenciou de maneira significativa a legislação sobre desenvolvimento de conhecimento individual e institucional, porém para área contábil o capital intelectual como ativo intangível ainda é restrito ao conhecimento patenteável e com valor comercial. Isso reflete no comportamento dos gestores que diminuem os esforços em controlar esse capital intelectual e inclui-lo nos sistemas gerencias, uma vez que essa não será objeto de avaliação externa e social. Apesar da manifestação social, representada pelas legislações sobre o tema, indicar que há influência nas diretrizes é necessário verificar como as instituições incluem o capital intelectual nos sistemas de controle e para lidar com as contingências do atual cenário econômico.

A Teoria da Contingência destaca que não há nada absoluto nas organizações, tudo é relativo; variáveis independentes como o ambiente e tecnologia - e até o capital intelectual, abordado neste trabalho provocam adaptação através de variáveis dependentes a essas mudanças, como, por exemplo, a concepção de sistemas de controle, ou mesmo preocupação constante com o desempenho (Camacho, 2010). No contexto das universidades públicas, percebe-se que a variável capital intelectual, tanto cria uma necessidade do seu próprio gerenciamento quanto modifica a forma como os sistemas são utilizados.

Para o campo do conhecimento é relevante discutimos a necessidade de criação de uma ponte entre os extremos (CI como elemento importante na área privada) e (CI elemento tratado de forma dispersa nas diretrizes governamentais). $\mathrm{O}$ estudo traz à baila a necessidade de controle e gerenciamento do capital intelectual bem como os estímulos do seu desenvolvimento na área pública em especial IFES. Embora iniciativas claras de controle são desconhecidas, estimula-se um maior volume de estudos acerca desta temática. De forma gerencial o estudo contribui elencando um problema incipiente da área pública. Investir em educação aparentemente é um tema aclamado pelo senso comum, mas aqui contribuise na discussão sobre o potencial inexplorado de capital intelectual de instituiçõos dessa natureza.

Como limite da presente pesquisa, destaca-se a escassez de trabalhos acadêmicos sobre a temática ora abordada, o que indica, indício de novas oportunidades de pesquisa. Este estudo contribui para a literatura da teoria contingencial no sentido de apresentar uma nova perspectiva sobre o capital intelectual, contido em instituições públicas de ensino superior, sua interação com os sistemas de controle. Outra contribuição é iniciar a discussão sobre as iniciativas governamentais acerca dessa variável CI, sendo assim atinge-se o objetivo relacionando de maneira incipiente com a contingencia e com a IFEs. Deste modo, como sugestão de pesquisas futuras, sugere-se investigação em profundidade sobre a existência de controles de capital intelectual em IES públicas. Sugere-se, também, investigar percepção dos contadores públicos sobre a importância dos ativos intangíveis nas instituições públicas de ensino superior. 


\section{REFERÊNCIAS}

Bertero, C. O. (2011). Réplica 2 - o que é um ensaio teórico? Réplica a Francis Kanashiro Meneghetti. Revista de Administração Contemporânea, 15(2), 338-342.

Beuren, I., \& Macohon, E. (2011). Institucionalização de hábitos e rotinas na contabilidade gerencial à luz da teoria da contingência: Um estudo em indústrias de móveis em São Bento do Sul. Revista Portuguesa e Brasileira de Gestão, 10(1-2), 78-91.

Bontis, N. (1998). Intellectual capital: an exploratory study that develops measures and models. Management decision, 36(2), 63-76.

Bonacim, C. A., \& Araujo, A. M. D. (2010). Influência do capital intelectual na avaliação de desempenho aplicada ao setor hospitalar. Ciência \& Saúde Coletiva, Rio de Janeiro, 15(supl 1), 1249-1261.

Bushfield, S. Ref 11.01 The Relationship between Human Capital and Enterprising'Public Services: A Critical Review of the Literature and Proposals for Further Research.

Calix, C. G., Vigier, H. P., \& Briozzo, A. E. (2015) Capital intelectual y otros determinantes de la ventaja competitiva en empresas exportadoras de la zona norte de Honduras, Suma de Negocios, v.6, n.14, July-December 2015, p.130-137, ISSN 2215910X,

http://dx.doi.org/10.1016/j.sumneg.2015.10.005

Camacho, R. R. (2010). Fatores condicionantes da gestão de custos interorganizacionais na cadeia de valor de hospitais privados no Brasil: uma abordagem à luz da Teoria da Contingência. 2010. 156 f. Tese de Doutorado, Universidade de São Paulo, SP, Brasil. Disponível: http://www.teses.usp.br/teses/disponiveis/12/12136/ tde-22012011-164307/en.php.

Córcoles, Y. R. \& Ponce, Á. T. Cost-benefit analysis of intellectual capital disclosure: University stakeholders' view. Revista de Contabilidad Spanish Accounting Review (RC-SAR), v.16, n.2, June-December 2013, p.106-117, ISSN 1138-4891, http://dx.doi.org/10.1016/j.rcsar.2013.07.001.

CGU. Controladoria-Geral da União, 2015. Disponível em: <http://www.cgu.gov.br/assuntos/controlesocial>. Acesso em: 15 outubro 2015.

Chandler, A. D. (1990). Strategy and structure: Chapters in the history of the industrial enterprise. MIT, Massachusetts: MIT press.
Dierickx, I., \& Cool, K. (1989). Asset stock accumulation and sustainability of competitive advantage. Management science, 35(12), 15041511

Drucker, P. F. (1993). Gestão para o Futuro. London: Routledge.

Fagundes, J. A., Soler, C. C., Feliu, V. R., \& Lavarda, C. E. F. (2010). Proposta de pesquisa em contabilidade: considerações sobre a teoria da contingência. Revista de Contabilidade do Mestrado em Ciências Contábeis da UERJ, 13(2), $1-13$.

García-Ayuso, M. (2003). Intangibles: Lessons from the past and a look into the future. Journal of intellectual capital, 4(4), 597-604.

Guerreiro, R., Pereira, C. A., \& Rezende, A. J. (2008). Em busca do entendimento da formação dos hábitos e das rotinas da contabilidade gerencial: um estudo de caso. Revista de administração Mackenzie, 7(2), 78-101.

Hayes, S. C. (1976). The role of approach contingencies in phobic behavior. Behavior Therapy, Volume 7, Issue 1, January 1976, Pages 28-36, ISSN 0005-7894, http://dx.doi.org/10.1016/S0005-7894(76)80216-X.

Hayes, D. C. (1977). The contingency theory of managerial accounting. Accounting review, 22-39.

Junqueira, E. R. (2010). Perfil do sistema de controle gerencial sob a perspectiva da teoria da contingência. 2010. 156 f. Tese de Doutorado, Universidade de São Paulo, SP, Brasil. Disponível: http://www.teses.usp.br/teses/disponiveis/12/12136/ tde-10052010-143511/en.php

Kaplan, R. S., \& Norton, D. P. (2004). Strategy maps: Converting intangible assets into tangible outcomes. Harvard Business Press.

Leitner, K. H. (2004). Intellectual capital reporting for universities: conceptual background and application for Austrian universities. Journal Research Evaluation, v. 13 , n.2, p. $129-140$ doi= $10.3152 / 147154404781776464$.

Marques, K. C. M. (2012). Custeio alvo à luz da teoria da contingência e da nova sociologia institucional: estudo de caso sobre sua adoção, implementação e uso. 2012. 1289 f. Tese de Doutorado, Universidade de São Paulo, SP, Brasil. Disponível: http://www.teses.usp.br/teses/disponiveis/12/12136/ tde-29012013-190708/en.php 
Meneghetti, F. K. (2011). What is a theoretical essay?. Revista de Administração Contemporânea, 15(2), 320-332.

Moore, M. H. (2003). The public value scorecard: a rejoinder and an alternative to'strategic performance measurement and management in non-profit organizations' by Robert Kaplan. Hauser Center for Nonprofit Organizations Working Paper, (18).

Nelson, R. R., \& Winter, S. G. (2009). An evolutionary theory of economic change. Harvard University Press.

Otley, D. (2016). The contingency theory of management accounting and control: 1980-2014, Management Accounting Research, Volume 31, June 2016, p. 45-62, ISSN 1044-5005, http://dx.doi.org/10.1016/j.mar.2016.02.001.

Raupp, F. M. \& Beuren, I. M. (2009). Metodologia da pesquisa aplicável às ciências sociais. In: Beuren, Ilse M. (ed.). Como elaborar trabalhos monográficos em contabilidade: teoria e prática, pp. 76-97 São Paulo: Atlas.

Stefano, N. M., Casarotto Filho, N., Freitas, M. D. C. D., \& Martinez, M. A. T. (2014). Gestão de ativos intangíveis: implicações e relações da gestão do conhecimento e capital intelectual. Perspectivas em Gestão \& Conhecimento, 4(1), 22-37.
Stoker, G. (2006). Public value management a new narrative for networked governance? The American review of public administration, 36(1), 41-57.

Subramaniam, M., \& Youndt, M. A. (2005). The influence of intellectual capital on the types of innovative capabilities. Academy of Management Journal, 48(3), 450-463.

Romero, F. T. (2016). Información de los recursos intangibles ocultos: ¿memorias de sostenibilidad o informe anual?, European Research on Management and Business Economics, Volume 22, Issue 2, May-August 2016, Pages 101-109, ISSN 2444-8834,

http://dx.doi.org/10.1016/j.iedee.2015.06.001.

TCU. Tribunal de Contas da União, 2015. Disponivel em: <http://portal.tcu.gov.br/cidadao/cidadao.htm>. Acesso em: 15 outubro 2015.

Waterhouse, J. H., \& Tiessen, P. (1978). A contingency framework for management accounting systems research. Accounting, Organizations and Society, 3(1), 65-76.

Widener, S. K. (2004). An empirical investigation of the relation between the use of strategic human capital and the design of the management control system. Accounting, Organizations and Society, 29(3), 377-399. 